\title{
MANAJEMEN PEMBELAJARAN DIRECT INSTRUCTION DALAM PRAKTIKUM IPA SEBAGAI KUNCI KEBERHASILAN GURU IPA DI LABORATORIUM
}

\author{
Budiyono Saputro \\ budiyono_saputro@yahoo.com \\ Jurusan Tadris IPA IAIN Salatiga
}

\begin{abstract}
ABSTRAK
Berdasarkan kenyataan di lapangan guru Ilmu Pengetahuan Alam(IPA) tidak terlepas dari pembelajaran praktikum. Pembelajaran Praktikum IPA memerlukan perencanaan, pelaksanaan dan evaluasi. Aspek perencanaan pembelajaran praktikum memerlukan waktu yang lebih dalam membuat Lembar Kerja Siswa (LKS), mempersiapkan alat dan bahan praktikum, dan alat evaluasi yang meliputi tiga ranah pendidikan yaitu: kognitif, afektif dan psikomotorik. Pembelajaran praktikum IPA lebih sesuai disampaikan dengan pembelajaran direct instruction. Perencanaan dan pelaksanaan pembelajaran direct instruction dalam praktikum IPA meliputi lima phase: phase pertama adalah guru menetapkan tujuan praktikum IPA, phase kedua guru mempersiapkan peragaan pengetahuan dan keterampilan sebelum praktikum dilaksanakan, phase ketiga guru mempersiapkan latihan terbimbing, phase keempat guru mempersiapkan umpan balik pembelajaran praktikum sesuai materi yang dilaksanakan, phase kelima guru mempersiapkan latihan lanjut dan transfer belajar. Evaluasi pembelajaran direct instruction dalam pembelajaran praktikum IPA dengan melaksanakan pre tes, pengamatan, pos tes dan penilaian hasil laporan praktikum. Dengan demikian kunci sukses guru IPA di laboratorium adalah guru melaksanakan manajemen pembelajaran praktikum IPA dengan benar.
\end{abstract}

Kata kunci: direct instruction, manajemen, pembelajaran IPA

\section{PENDAHULUAN}

Pembelajaran praktikum di laboratorium tidak selalu berjalan dengan lancar. Ketidakberhasilan dalam pembelajaran di laboratorium satu diantaranya adalah adanya mismanajemen pembelajaran. Manajemen pembelajaran penting dilakukan oleh guru dikarenakan dengan melakukan manajemen pembelajaran, minimal tiga komponen/unsur manajemen yang meliputi perencanaan, pelakasanaan dan evaluasi matang dalam persiapannya. Dengan demikian menunjukkan manajemen pembelajaran telah dilakukan yang sebenarnya. Berdasarkan kenyataan di lapangan guru IPA tidak terlepas dari pembelajaran praktikum. Pembelajaran Praktikum memerlukan perencanaan, pelaksanaan dan evaluasi yang berbeda dari pembelajaran teori. Aspek perencanaan pembelajaran praktikum memerlukan waktu yang lebih dalam membuat Lembar Kerja Siswa (LKS), mempersiapkan alat dan bahan praktikum, dan alat evaluasi yang meliputi tiga ranah pendidikan yaitu: kognitif, afektif dan psikomotorik. Kognitif dengan membuat soal pre tes dan pos tes. Aspek afektif dilakukan dengan membuat dan menggunakan lembar observasi dan psikomotorik juga dengan membuat lembar observasi/lembar pengamatan. 
Pelaksanaan pembelajaran praktikum dengan melakukan prosedur yang sistematis sebagai berikut: (1) pre tes, (2) responsi, (3) penyiapan alat bahan praktek, (4) kegiatan praktek dengan bimbingan guru, (5) pengamatan, (6) diskusi hasil pengamatan, (7) kesimpulan dan (8) pembuatan laporan serta (9) pos tes. Aspek evaluasi adalah guru melakukan penilaian dengan mengunakan alat tes berupa soal dan lembar observasi. Ketiga aspek yang terdiri dari kognitif, afektif dan psikomotorik perlu manajemen yang handal agar pembelajaran dapat berhasil.

Pernyataan bahwa manajemen pembelajaran merupakan hal yang penting dilakukan oleh guru didukung hasil penelitian yang dilakukan oleh Saputro (2013) bahwa model manajemen pembelajaran direct instruction berfokus film dan panduan yang lebih mudah untuk dipahami dan dijalankan. Tahapan manajemennya, yaitu: perencanaan, pelaksanaan, dan evaluasi. Hal tersebut terbukti pada hasil uji terbatas bahwa terdapat peningkatan antara hasil pretes dengan postes mahasiswa PGMI (uji wilxocon $=0.00, \mathrm{p}$ $<0.05$ ). Simpulan penelitian adalah model manajemen pembelajaran direct instruction berfokus film efektif dapat meningkatkan kemampuan mahasiswa dalam praktikum IPA. Senada dengan penelitian lain yang dilakukan oleh Saputro (2013) manajemen perlu dilakukan dalam pelatihan bagi guru sebagai berikut: model manajemen pelatihan alat peraga secara kontekstual efektif dapat meningkatan kompetensi pedagogik guru IPA MI di Kecamatan Ngablak Kabupaten Magelang. Efektifitas model manajemen pelatihan alat peraga secara kontekstual dapat ditunjukkan pada: (1) Hasil penilaian model manajemen pelatihan alat peraga IPA secara kontekstual oleh peserta dengan kategori sangat baik dari setiap unsur model mana- jemen, (2) peningkatan kemampuan pretes dan postes peserta, paired t test diperoleh hasil signifikansi $0,000<0,05$, dengan demikian dapat diambil kesimpulan bahwa terdapat perbedaan antara hasil pretes dengan postes, (3) hasil pengamatan kemampuan penggunaan alat peraga IPA peserta pascapelatihan di sekolah masing-masing dengan hasil kompeten.

Berdasarkan hasil penelitian tersebut di atas, maka urgensi guru dalam melakukan manajemen pembelajaran IPA sangat dibutuhkan. Unsur manajemen perencanaan merupakan hal penting yang dilakukan oleh guru. Perencanaan pembelajaran praktikum IPA wujud kongretnya adalah Rencana Pelaksanaan Pembelajaran (RPP), pembuatan Lembar Kerja Siswa (LKS) dan penyiapan alat, bahan praktikum. RPP dipersiapakan oleh guru sejak awal sebelum proses pembelajaran dimulai. Adapun ruang lingkup RPP terdiri dari berbagai unsur yang saling terkait dan menunjukkan persiapan guru dalam mengajar. Pelaksanaan pembelajaran praktikum dilaksanakan guru di laboratorium dengan melakukan prosedur dari responsi sampai dengan komunikasi/diskusi hasil pengamatan serta kesimpulan hasil pengamatan. Evaluasi merupakan unsur manajemen yang dilakukan oleh guru dalam pembelajaran dengan tujuan untuk mengukur keberhasilan pembelajaran. Keberhasilan dalam pembelajaran praktikum IPA meliputi aspek kognitif, afektif dan psikomotorik.

\section{URGENSI MANAJEMEN DALAM PEMBELAJARAN PRAKTIKUM BAGI GURU IPA}

Manajemen merupakan fundamen dalam menentukan keberhasilan dalam kegiatan. Pembelajaran Praktikum merupakan kegiatan akademik yang dilakukan di sekolah. 
Pembelajaran praktikum memerlukan manajemen. Beberapa teori dasar manajemen seperti yang pendapat para ahli Terry, Hanry L. Sisk. Hanry L. Sisk mendefinisikan Management is the coordination of all resources through the processes of planning, organizing, directing and controlling in order to attain stted objectivies. Artinya manajemen adalah Pengkoordinasian untuk semua sumber-sumber melalui proses-proses perencanaan, pengorganisasian, kepemimpinan dan pengawasan di dalam ketertiban untuk tujuan. Manajemen merupakan suatu sistem dan memiliki komponen. Terry (1977: 4) "management is a distinct process consisting of planning, organizing, actuating, and controlling, performed to determine and accomplish stated objectives by the use of human beings and other resources". Artinya manajemen merupakan sebuah proses yang khas, yang terdiri dari tindakan-tindakan:perencanaan, pengorganisasian, penggiatan dan pengawasan, yang dilakukan untuk menentukan serta mencapai sasaran-sasaran yang telah ditetapkan melalui pemanfaatan sumber daya manusia dan sumber-sumber lain. Mulyono (2009: 18) menyatakan "manajemen adalah sebuah proses yang khas yang terdiri dari perencanaan, pengorganisasian, penggerakan dan pengawasan serta evaluasi yang dilakukan pihak pengelola organisasi untuk mencapai tujuan bersama dengan memberdayakan sumber daya lainnya". Fattah (2009: 1) "manajemen diartikan sebagai proses merencana, mengorganisasi, memimpin dan mengendalikan upaya organisasi dengan segala aspeknya agar tujuan organisasi tercapai secara efektif dan efisien". Berdasarkan pendapat ahli tentang manajemen tersebut di atas, dapat penulis simpulkan bahwa manajemen merupakan hal yang penting dilakukan dalam kegiatan yang meliputi tiga unsur utama yaitu: perencanaan, pelaksanaan dan evaluasi. Ketiga unsur tersebut merupakan sistem yang saling terkait dan dilakukan secara sistematis.

Manajemen pembelajaran menjadi sangat penting dilakukan dengan tujuan untuk mencapai tujuan pembelajaran yang efektif dan efisien. Menurut Mulyasa (2003: 21) lemahnya manajemen pendidikan memberi dampak terhadap efisiensi internal pendidikan yang terlihat dari sejumlah peserta didik yang putus sekolah atau tinggal kelas. Implementasi manajemen dalam pembelajaran di kelas dan di laboratorium dapat menjadikan pembelajaran yang efektif dan efisien. Hal tersebut senada dengan Danim, S (2002) bahwa manajemen kelas sebagai proses mengorganisasikan segala sumber daya kelas bagi terciptanya proses pembelajaran yang efektif dan efisien. Pembelajaran memerlukan manajemen yang meliputi: perencanaan, pelaksanaan dan evaluasi, sehingga dengan demikian proses belajar mengajar dan tujuan pembelajaran dapat tercapai dengan maksimal. Esensi dan eksistensi manajemen kelas dalam pembelajaran praktikum IPA dapat dijadikan sebagai indikator keberhasilan dalam proses pembelajaran praktikum IPA di laboratorium. Yulaelawati (2004) konsep manajemen pembelajaran dapat diartikan proses mengelola yang meliputi kegiatan perencanaan, pengorganisasian, pengendalian (pengarahan) dan pengevaluasian kegiatan yang berkaitan dengan proses membelajarkan si pebelajar dengan mengikutsertakan berbagai faktor di dalamnya guna mencapai tujuan. Dalam "memanaje" atau mengelola pembelajaran, manajer dalam hal ini guru melaksanakan berbagai langkah kegiatan mulai dari perencanaan, pengorganisasian, pelaksanaan dan evaluasi pembelajaran yang dilakukan. Pengertian manajemen pembelajaran demi- 
kian dapat diartikan secara luas dalam arti mencakup keseluruhan kegiatan bagaimana membelajarkan siswa mulai dari perencanaan pembelajaran sampai pada penilaian pembelajaran.

Berdasarkan uraian di atas, maka manajemen pembelajaran merupakan kegiatan yang dilakukan oleh guru dalam merencanakan, melaksanakan, dan mengevaluasi pembelajaran guna mencapai tujuan pembelajaran secara efektif dan efesien. Manajemen dalam pembelajaran yang meliputi: perencanaan pembelajaran, pelaksanaan pembelajaran dan evaluasi pembelajaran. Adapun manajemen pembelajaran praktikum IPA untuk mencapai tujuan pembelajaran praktikum IPA yang efektif dan efisien adalah sebagai berikut.

1. Perencanaan Pembelajaran Praktikum IPA

Perencanaan praktikum tertuang dalam RPP. Jalannya praktikum dipandu dalam LKS. Majid, A (2005) Perencanaan adalah proses penetapan dan pemanfaatan sumber daya secara terpadu yang diharapkan dapat menunjang kegiatan-kegiatan dan upayaupaya yang akan dilaksanakan secara efisien dan efektif dalam mencapai tujuan. Pembelajaran praktikum IPA lebih sesuai disampaikan dengan pembelajaran direct instruction. Adapun perencanaan pembelajaran direct instruction dalam pembelajaran IPA adalah sebagai berikut.

Tabel 1 Perencanaan Pembelajaran Direct Instruction dalam Praktikum IPA

\begin{tabular}{cl}
\hline Phase & \multicolumn{1}{c}{ Perencanaan Pembelajaran Praktikum IPA } \\
\hline Phase 1 & Menetapkan tujuan dan menetapkan set \\
Phase 2 & Memperagakan pengetahuan atau keterampilan \\
Phase 3 & Memberikan latihan-latihan terbimbing \\
Phase 4 & Meninjau kembali dan memberi balikan \\
Phase 5 & Memberikan latihan lanjut dan transfer belajar \\
\hline
\end{tabular}

Perencanaan pembelajaran praktikum IPA pada phase 1 adalah guru menetapkan tujuan praktikum IPA. Phase 2 dengan mempersiap- kan peragaan pengetahuan dan keterampilan sebelum praktikum dilaksanakan. Phase 3 guru mempersiapkan latihan terbimbing. Phase 4 guru mempersiapkan umpan balik pembelajaran praktikum sesuai materi yang dilaksanakan. Phase 5 guru mempersiapkan lantihan lanjut dan transfer belajar.

2. Pelaksanaan Pembelajaran Praktikum IPA

Pelaksanaan praktikum IPA berpedoman pada perencanaan praktikum yang telah dilakukan oleh guru. Pelaksanaaan praktikum IPA dengan pembelajaran direct instruction adalah sesuai syntax sesuai tabel 2 .

Proses kegiatan belajar mengajar merupakan interaksi antara guru dengan siswa. Pelaksanaan pembelajaran praktikum sesuai syntax pada tabel 2. Pelaksanaan pembelajaran praktikum IPA sesuai tersebut pada syntax direct instruction memuat kegiatan pengelolaan dan kepemimpinan pembelajaran yang dilakukan guru di laboratorium dan pengelolaan peserta didik. Pada syntax pembelajaran direct instruction juga memuat kegiatan pengorganisasian yang dilakukan guru IPA. Oleh karena itu dalam hal pelaksanaan pembelajaran praktikum mencakup pengelolaan kelas dan peserta didik serta pengelolaan laboratorium. Hal tersebut senada dengan Majid, A (2005: 165) pengelolaan kelas sedikitnya terdapat tujuh hal yang harus diperhatikan, yaitu ruang belajar, pengaturan sarana belajar, susunan tempat duduk, yaitu ruang belajar, pengaturan sarana belajar, susunan tempat duduk, penerangan, suhu, pemanasan sebelum masuk ke materi yang akan dipelajari (pembentukan dan pengembangan kompetensi) dan bina suasana dalam pembelajaran.

3. Evaluasi Pembelajaran Praktikum IPA

Evaluasi pembelajaran praktikum IPA dilakukan pada awal, tengah dan akhir 
Tabel 2 Syntax Pembelajaran Direct Instruction dalam Praktikum IPA

\begin{tabular}{|c|c|}
\hline Phase & Kegiatan Dosen \\
\hline $\begin{array}{l}\text { Phase } 1 \\
\text { Menetapkan tujuan dan menetapkan set }\end{array}$ & $\begin{array}{l}\text { 1. Memberikan penjelasan tujuan pembelajaran } s \\
\text { materi praktikum IPA. } \\
\text { 2. Memberikan informasi yang berhubungan den } \\
\text { materi praktikum agar siswa siap melakukan } \\
\text { praktikum dengan benar. }\end{array}$ \\
\hline $\begin{array}{l}\text { Phase } 2 \\
\text { Memperagakan pengetahuan atau } \\
\text { keterampilan }\end{array}$ & $\begin{array}{l}\text { Guru mendemonstrasikan keterampilan secara ben } \\
\text { sesuai materi praktikum. }\end{array}$ \\
\hline $\begin{array}{l}\text { Phase } 3 \\
\text { Memberikan latihan-latihan terbimbing }\end{array}$ & $\begin{array}{l}\text { Memberikan latihan langsung di laboratorium sesu } \\
\text { dengan materi praktikum. }\end{array}$ \\
\hline $\begin{array}{l}\text { Phase } 4 \\
\text { Meninjau kembali dan memberi } \\
\text { balikan }\end{array}$ & $\begin{array}{l}\text { 1. Mengoreksi hasil praktikum siswa. } \\
\text { 2. memberikan umpan balik. }\end{array}$ \\
\hline $\begin{array}{l}\text { Phase } 5 \\
\text { Memberikan latihan lanjut dan transfer } \\
\text { belajar }\end{array}$ & $\begin{array}{l}\text { Membentuk kondisi untuk latihan lebih lanjut den£ } \\
\text { materi praktikum dari lingkungan sekitar. }\end{array}$ \\
\hline
\end{tabular}

kegiatan praktikum IPA. Menurut Hamalik, O (2008: 156) Evaluasi merupakan suatu upaya untuk mengetahui berapa banyak halhal yang telah dimiliki oleh siswa dari halhal yang telah diajarkan oleh guru. Sedangkan Permendiknas Nomor 41 Tahun 2007 tentang standar proses bahwa evaluasi pembelajaran mencakup evaluasi hasil belajar dan evaluasi proses pembelajaran. Evaluasi hasil belajar menekankan pada diperolehnya informasi tentang perolehan siswa dalam mencapai tujuan pengajaran yang ditetapkan. Sedangkan evaluasi pembelajaran merupakan proses sistematis untuk memperoleh informasi tentang keefektifan proses pembelajaran dalam membantu siswa mencapai tujuan pengajaran secara optimal. Pembelajaran praktikum IPA pelaksanaan evaluasinya adalah dengan melaksanakan pre tes sebagai tolak ukur kemampuan awal sebelum mengikuti praktikum, pada saat praktikum IPA berlangsung melalui kegiatan pengamatan guru terhadap siswa dalam melakukan praktikum IPA yang meliputi kemampuan afektif dan psikomotorik.

\section{MANAJEMEN KUNCI SUKSES DALAM PENINGKATAN KOMPETENSI PROFESIONAL GURU DALAM PRAKTIKUM IPA}

Berdasarkan Permendiknas RI No. 16 Tahun 2007 mengatur tentang kualifikasi akademik dan Kompetensi Guru. Kualifikasi Akademik Guru IPA SMP/MTs adalah atau bentuk lain yang sederajat, harus memiliki kualifikasi akademik pendidikan minimum diploma empat (D-IV) atau sarjana (S1) program studi yang sesuai dengan mata pelajaran yang diajarkan/diampu, dan diperoleh dari program studi yang terakreditasi. Sedangkan Kualifikasi Akademik Guru IPA SMA/MA atau bentuk lain yang sederajat, harus memiliki kualifikasi akademik pendidikan minimum diploma empat (DIV) atau sarjana (S1) program studi yang sesuai dengan mata pelajaran yang diajarkan/diampu, dan diperoleh dari program studi yang terakreditasi. Kualifikasi Akademik Guru SMK/MAK atau bentuk lain yang sederajat, harus memiliki kualifikasi akademik pendidikan minimum 
Tabel 3 Syntax Evaluasi Pembelajaran Direct Instruction dalam Praktikum IPA

\begin{tabular}{|c|c|c|}
\hline Phase & Kegiatan Dosen & \multirow{5}{*}{$\begin{array}{l}\text { Guru melakukan } \\
\text { evaluasi dengan } \\
\text { pengamatan siswa } \\
\text { pada aspek afektif dan } \\
\text { psikomotorik. }\end{array}$} \\
\hline Pre tes & $\begin{array}{l}\text { 1. Membagikan soal pre tes. } \\
\text { 2. Mengawasi pelaksanaan pre } \\
\text { tes }\end{array}$ & \\
\hline $\begin{array}{l}\text { Phase } 1 \\
\text { Menetapkan tujuan dan } \\
\text { menetapkan set }\end{array}$ & $\begin{array}{l}\text { 1. Memberikan penjelasan tujuan } \\
\text { pembelajaran sesuai materi } \\
\text { praktikum IPA. }\end{array}$ & \\
\hline & $\begin{array}{l}\text { 2. Memberikan informasi yang } \\
\text { berhubungan dengan materi } \\
\text { praktikum agar siswa siap } \\
\text { melakukan praktikum dengan } \\
\text { benar }\end{array}$ & \\
\hline $\begin{array}{l}\text { Phase } 2 \\
\text { Memperagakan } \\
\text { pengetahuan atau } \\
\text { keterampilan }\end{array}$ & $\begin{array}{l}\text { Guru mendemonstrasikan } \\
\text { keterampilan secara benar sesuai } \\
\text { materi praktikum. }\end{array}$ & \\
\hline $\begin{array}{l}\text { Phase } 3 \\
\text { Memberikan latihan-latihan } \\
\text { terbimbing }\end{array}$ & $\begin{array}{l}\text { Memberikan latihan langsung di } \\
\text { laboratorium sesuai dengan materi } \\
\text { praktikum. }\end{array}$ & \\
\hline $\begin{array}{l}\text { Phase } 4 \\
\text { Meninjau kembali dan } \\
\text { memberi balikan }\end{array}$ & $\begin{array}{l}\text { 1. Mengoreksi hasil praktikum } \\
\text { siswa. } \\
\text { 2. memberikan umpan balik. }\end{array}$ & \\
\hline $\begin{array}{l}\text { Phase } 5 \\
\text { Memberikan latihan lanjut } \\
\text { dan transfer belajar }\end{array}$ & $\begin{array}{l}\text { Membentuk kondisi untuk latihan } \\
\text { lebih lanjut dengan materi } \\
\text { praktikum dari lingkungan sekitar. }\end{array}$ & \\
\hline Pre tes & $\begin{array}{l}\text { 1. Membagikan soal pos tes. } \\
\text { 2. Mengawasi pelaksanaan pos } \\
\text { tes }\end{array}$ & \\
\hline
\end{tabular}

diploma empat (D-IV) atau sarjana (S1) program studi yang sesuai dengan mata pelajaran yang diajarkan/diampu, dan diperoleh dari program studi yang terakreditasi. Sedang Kompetensi Permendiknas RI No. 16 Tahun 2007 bahwa kompetensi guru meliputi: kompetensi kepribadian, kompetensi sosial, kompetensi pedagogi dan kompetensi profesional.

Kompetensi menurut Wibowo (2010: 324) "adalah suatu kemampuan untuk melaksanakan atau melakukan suatu pekerjaan atau tugas yang dilandasi atas keterampilan dan pengetahuan serta didukung oleh sikap kerja yang dituntut oleh pekerjaan tersebut". Spencer and Spenser dalam Uno
(2010: 62) mendifinisikan "kompetensi adalah kemampuan sebagai karakteristik yang menonjol dari seseorang individu yang berhubungan dengan kinerja efektif dan atau superior dalam suatu pekerjaan atau situasi". Sedangkan definisi kompetensi menurut Sedarmayanti (2010: 126) "kompetensi diartikan sebagai kecakapan, ketrampilan dan kemampuan”. Menurut Kunandar (2011: 55) "kompetensi guru adalah seperangkat penguasaan kemampuan yang harus ada dalam diri guru agar dapat mewujudkan kinerjanya secara tepat dan efektif'. Saud (2009: 45) "kompetensi dipandang sebagai pilarnya atau teras kinerja dari suatu profesi". Menurut Hamalik, Oemar (1991: 32) bahwa 
tugas profesional guru adalah: (1) bertindak sebagai model bagi para anggotanya, (2) merangsang pemikiran dan tindakan, (3) memimpin perencanaan dalam mata pelajaran, (4) memberikan nasehat kepada executive teacher sesuai dengan kebutuhan tim, (5) membina dan memelihara literatur profesional dalam daerah pelajarannya, (6) Bertindak atau memberikan pelayanan sebagai manusia sumber dalam daerah pelajaran tertentu dengan referensi pada inservice training dan pengembangan kurikulum, (7) mengembangkan file kurikulum dalam daerah pelajaran tertentu dan mengajar di kelas-kelas yang paling besar, (8) memelihara hubungan dengan orang tua murid dan memberikan komentar atau laporan, (9) bertindak sebagai pengajar dalam timnya.

Menurut Uno (2009) bahwa guru yang profesional adalah guru yang memiliki seperangkat kompetensi (pengetahuan, keterampilan, dan perilaku) yang harus dimiliki, dihayati, dan dikuasai oleh guru dalam melaksanakan tugas keprofesionalanya. Kompetensi guru di Indonesia yang telah dikembangkan oleh Proyek Pembinaan Pendidikan Guru (P3G) Departemen Pendidikan dan Kebudayaan yaitu sepuluh kompetensi guru sebagai berikut: (1) menguasai bahan, (2) mengelola program belajar mengajar, (3) mengelola kelas, (4) menggunakan media/sumber belajar, (5) menguasai landasan kependidikan, (6) mengelola interaksi belajar mengajar, (7) menilai prestasi belajar, (8) mengenal fungsi dan layanan bimbingan penyuluhan, (9) mengenal dan menyelenggarakan administrasi sekolah dan (10) memahami dan menafsirkan hasil penelitian guna keperluan pengajaran.

Kompetensi profesional guru dapat dicapai dengan berbagai upaya. Satu diantara solusi dalam rangka peningkatan kompetensi profesional melalui pelatihan. Hasil penelitian Saputro (2012) bahwa model manajemen pelatihan IPA terpadu efektif dapat meningkatan kemampuan profesional guru IPA dalam pembelajaran IPA terpadu. Hal tersebut terbukti dengan tercapainya kompetensi profesional dalam penyampaian pembelajaran IPA terpadu pasca pelatihan IPA terpadu dari tamatan pelatihan dengan rerata 4,68 (sangat profesional). Secara umum model manajemen pelatihan IPA terpadu lebih baik, lebih mudah dipahami dan mudah dijalankan serta lebih lengkap unsur manajemennya yaitu: perencanaan, pengorganisasian, pelaksanaan, evaluasi, monitoring serta tindak lanjut pasca pelatihan. Senada dengan Uno (2009) dalam kegiatan profesionalnya, guru harus memiliki kemampuan untuk merencanakan program pembelajaran dan kemampuan untuk melaksanakan pembelajaran. Kemampuan tersebut diperoleh dengan latihan yang berkesinambungan, baik pada masa pendidikan prajabatan maupun pada masa pendidikan dalam jabatan.

Berdasarkan Permendiknas RI No. 16 Tahun 2007 Kompetensi Profesional guru IPA adalah seperti pada tabel 4 .

\section{SIMPULAN}

Berdasarkan latar belakang dan uraian tersebut di atas, maka dapat disimpulkan bahwa kenyataan di lapangan guru Ilmu Pengetahuan Alam (IPA) tidak terlepas dari pembelajaran praktikum. Pembelajaran praktikum IPA lebih sesuai disampaikan dengan pembelajaran direct instruction. Manajemen pembelajaran direct instruction dalam praktikum IPA meliputi: perencanaan, pelaksanaan dan evaluasi. Diskripsi manajemen pembelajaran direct instruction dalam 
Satya Widya, Vol. 32, No.1. Juni 2016: 1-10

Tabel 4 Matrik Kompetensi Profesional Guru IPA

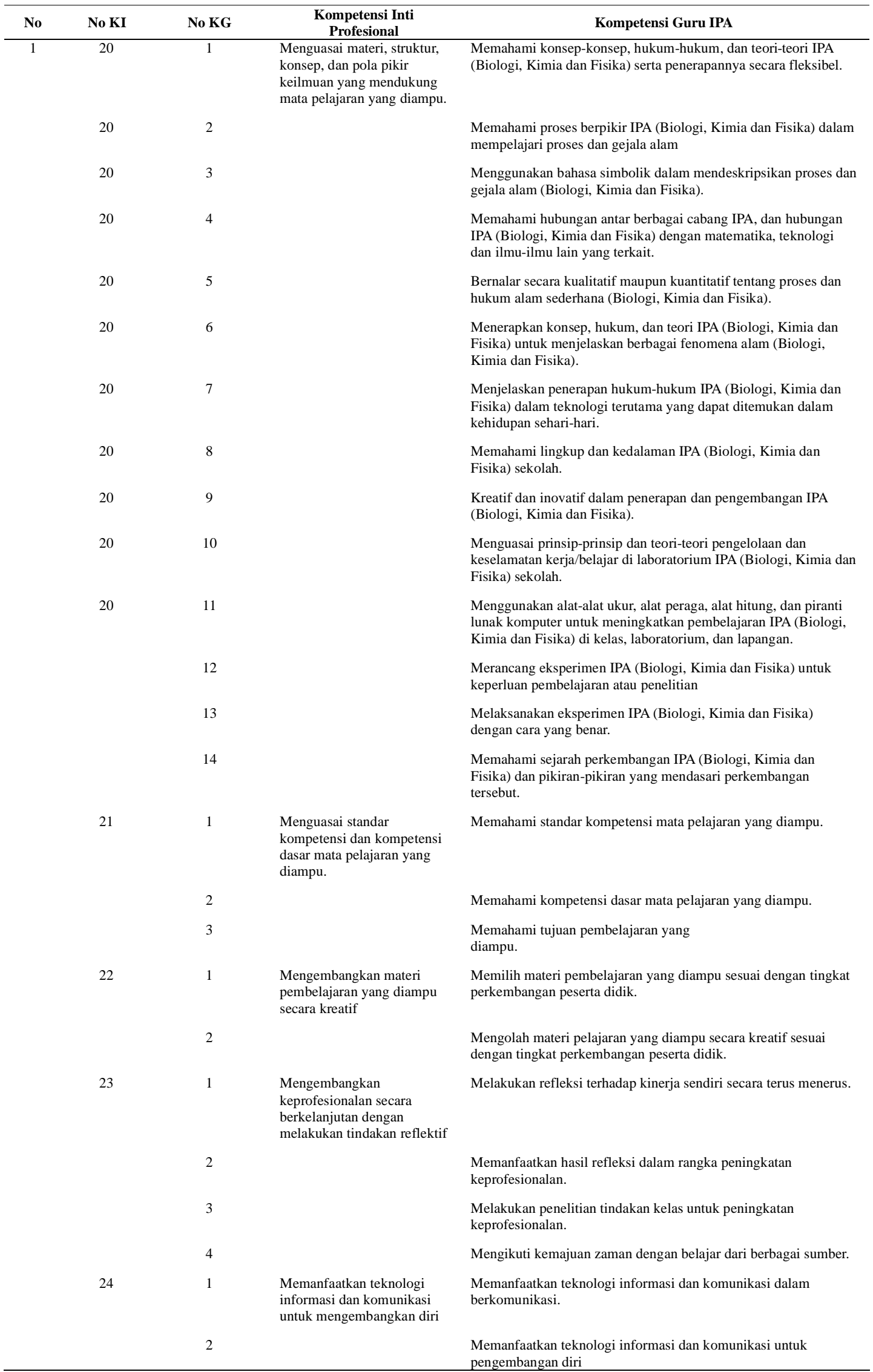


praktikum IPA adalah perencanaan dan pelaksanaan yang terdiri dari lima phase sebagai berikut: phase pertama adalah guru menetapkan tujuan praktikum IPA, phase kedua guru mempersiapkan peragaan pengetahuan dan keterampilan sebelum praktikum dilaksanakan, phase ketiga guru mempersiapkan latihan terbimbing, phase keempat guru mempersiapkan umpan balik pembelajaran praktikum sesuai materi yang dilaksanakan, phase kelima guru mempersiapkan latihan lanjut dan transfer belajar. Evaluasi pembelajaran direct instruction dalam pembelajaran praktikum IPA dengan melaksanakan pre tes, pengamatan, pos tes dan penilaian hasil laporan praktikum. Dengan demikian kunci sukses guru IPAdi laboratorium adalah guru melaksanakan manajemen pembelajaran praktikum IPA dengan benar.

\section{DAFTAR PUSTAKA}

Danim, Sudarwan. 2002. Inovasi Pendidikan Dalam Upaya Peningkatan Profesionalisme Tenaga Kependidikan. Bandung. Pustaka Setia.

Ella Yulaelawati. 2004. Kurikulum dan Pembelajaran. Filosofi Teori dan Aplikasi. Jakarta. Pakar Raya.

Fattah, Nanang. 2009. Landasan Manajemen Pendidikan. Bandung: Remaja Rosda Karya.

Hamalik, Oemar. 1991. Pendidikan Guru, Konsep dan Strategi. Bandung. Mandar Maju.

Hamalik, Oemar. 2008. Kurikulum dan Pembelajaran. Jakarta. Bumi Aksara.

Hanry L. Sisk. 1969. Principles of Management a System Appoach to The Management Proces. Chicago. Publishing Company.
Majid, Abdul. 2005. Perencanaan Pembelajaran: Mengembangkan Standar Kompetensi Guru. Bandung. Remaja Rosdakarya.

Mulyono. 2009. Manajemen Administrasi dan Organisasi Pendidikan. Jogjakarta: Ar-Ruzz Media.

Mulyasa. 2005. Menjadi Kepala Sekolah Profesional. Bandung. Rosda Karya.

Permendiknas RI Nomor 41 Tahun 2007 tentang standar proses.

Permendiknas RI Nomor 16 Tahun 2007 mengatur tentang kualifikasi akademik dan Kompetensi Guru.

Saputro, B. 2013. Pengembangan Model Manajemen Pembelajaran Direct Instruction berfokus Film dalam Pengantar Praktikum IPA Materi Uji Makanan yang Mengandung Karbohidrat pada Mahasiswa PGMI STAIN Salatiga Tahun 2013

Saputro, B. 2012. Pengembangan Model Manajemen Pelatihan IPA Terpadu dalam Rangka Peningkatan Kemampuan Profesional bagi Guru IPA SMP SeKabupaten Kudus. Disertasi. UNNES Semarang.

Saputro, B. 2013. Efektifitas Model Manajemen Pelatihan Alat Peraga IPA Melalui Pendekatan Kontekstual dalam rangka Peningkatan Kompetensi Pedagogik Guru IPA Madrasah Ibtidaiyah (MI) di Kecamatan Ngablak Kabupaten Magelang. Penelitian Individual. DIPA STAIN Salatiga.

Saud, U. S. 2009. Pengembangan Profesi Guru. Bandung: Alfabeta.

Sedarmayanti. 2010. Manajemen Sumber Daya Manusia Reformasi Birokrasi dan Manajemen Pegawai Negeri Sipil. Bandung: Refika Aditama. 
Satya Widya, Vol. 32, No.1. Juni 2016: 1-10

Terry, G. R. 1977. Principles of Management. 7rd ed. United State of America: Illionis Richard D. Irwin, Inc.

Uno, H. B. 2010. Profesi Kependidikan Problema, Solusi, dan Reformasi Pendidikan di Indonesia. Jakarta: Bumi Aksara.
Wibowo. 2010. Manajemen Kinerja Edisi Ketiga. Jakarta: Rajawali Press. 